\title{
Shopping Carts and Student Employees: How Student Committees Can Bring Innovative Ideas to Academic Libraries
}

Quinn Galbraith

Brigham Young University, quinn_galbraith@byu.edu

Sara D. Smith

Brigham Young University, saradsmith@byu.edu

Follow this and additional works at: https://scholarsarchive.byu.edu/facpub

Part of the Library and Information Science Commons

\section{Original Publication Citation}

Smith, S. D., \& Galbraith, Q. (2011). Shopping carts and student employees How student committees can bring innovative ideas to academic libraries. College \& Research Libraries News, 72(7), 394-397.

\section{BYU ScholarsArchive Citation}

Galbraith, Quinn and Smith, Sara D., "Shopping Carts and Student Employees: How Student Committees Can Bring Innovative Ideas to Academic Libraries" (2011). Faculty Publications. 1657.

https://scholarsarchive.byu.edu/facpub/1657 


\section{Shopping carts and student employees}

\section{How student committees can bring innovative ideas to academic libraries}

I n 1999, ABC's Nightline asked IDEO, a

well-known innovation and design consultancy, to redesign the shopping cart in five days. While the challenge of re-imagining a cultural icon "inexplicably stuck in a sort of an innovation limbo" ${ }^{1}$ drew enough interest, even more compelling was the process the IDEO team used to research, brainstorm, and design the new model.

The IDEO team threw out middle-management hierarchies based on experience or seniority - the project leader, who had only worked with IDEO for six years, was chosen for his skill in leading groups. The team members came from many disciplines, including psychology, architecture, linguistics, business, and industrial design; all stood as equals. After brainstorming issues like theft and child safety, the team split up into groups to interview grocery store shoppers, managers, and workers. Based on their research, each group designed a model, and then together the team designed a final model that incorporated the best of each group's ideas. Some of the early ideas were a little outlandish-Velcro children's seats, for example-but the final design was surprisingly functional, original, and aesthetically pleasing.

The Nightline program featuring IDEO is used today to teach organizations how to create a culture of innovation: "we all have a creative side, and it can flourish if you spawn a culture to encourage it, one that embraces risks and wild ideas and tolerates the occasional failure."2
Every organization needs to generate new, innovative ideas-and for academic libraries, going to the student employees may be the key to brainstorming the best ideas to improve services and meet patron needs. The Harold B. Lee Library at Brigham Young University (BYU) organized a group of student employees called the Library Student Advisory Council (LSAC), which meets once a week to generate ideas and research solutions to problems they and administration have identified. The committee uses a process similar to IDEO's - and we've seen similarly innovative and successful results.

The idea of student advisory committees in academic libraries is not new-many libraries have formed student groups to provide feedback and suggestions, to help publicize, and to better understand the needs and preferences of the library's primary user group. Several libraries have published on their efforts. Texas A\&M University General Libraries established its Student Advisory Committee because the library wanted to give students a say in how the library-use fee paid with tuition is spent. ${ }^{3}$ The Pennsylvania State-Schuylkill Library Student Advisory Board, which is run as a universitysanctioned student club, develops ideas, provides feedback, and encourages other

Sara D. Smith is assistant in the human resources office, e-mail: saradsmith@gmail.com, and Quinn Galbraith is human resources manager at Brigham Young University's Lee Library, e-mail: quinn_galbraith@ byu.edu

๑ 2011 Sara D. Smith and Quinn Galbraith 
students to use library resources: "Students are excellent library advocates to their peers when they are well informed about the library's collections and services and have a clear, consistent message to share." ${ }^{4}$ Two Penn State-Schuylkill librarians have published a book about how to start and facilitate a library student advisory group. ${ }^{5}$ The library at Loyola University-New Orleans implemented a student committee "to get more input from its primary usersstudents."

These groups have lead to changes in their respective libraries, including revised food and drink policies, extended hours, and more multimedia resources. Lee Library's LSAC has similarly inspired changes to meet the needs of student patrons. One of the most significant and innovative changes has been the creation of a music zone. Committee members suggested that classical music be played in the library, because many students like to study with music.

A lower-traffic space in the library was selected, and now the "music zone" is a popular place for students to study. Use of this space has increased by almost 20 percent. ${ }^{7}$ Current projects include how to best advertise under-used services, how to make it easier for students to browse the DVD collection, and how to improve signage to best help students navigate the library's five floors.

Like other student advisory committees, LSAC functions as a focus group that library administration can consult to get feedback or to better understand how students will respond to new services or policies. LSAC has also influenced spending decisions, such as when administration was trying to decide whether to replace chairs in the library instruction computer labs. After sitting in these chairs, LSAC members decided they were comfortable enough and advised against spending thousands to purchase new chairs.

\section{How LSAC is unique}

In some ways, LSAC is not that different from student advisory groups at other universities.
The basic idea of gathering ideas and feedback from students is the same. The issues the students bring up are similar, too-eating in the library, collection requests, etc. But that is where many similarities end. Unlike most student groups, LSAC is not comprised of volunteers from around campus, but rather of student employees who, with the permission of their supervisors, work on the clock to attend meetings and complete assignments. Because the students participate in LSAC as part of their jobs, they are held to a higher level of accountability - and they need to be managed a little differently.

These students are organized more like independent work teams. Like IDEO's innovative work teams, there is no middlemanagement hierarchy. LSAC is overseen by a member of the administrative executive committee (who attends meetings more to observe than guide or contribute) and report on their projects directly to library administration.

LSAC is comprised of about 12 student employees from different majors and who work in different departments in the library-again, reminiscent of IDEO's diverse team. All student employees are invited to apply at the beginning of the semester, and can remain on the committee for up to two years. Members are selected by the LSAC president, who is usually self-nominated and approved by administration. The president sets meeting agendas and facilitates discussions.

LSAC's organization and method loosely mirrors the innovative process employed by IDEO, which includes the following steps:

1. Understand the market, the client, the technology, and perceptions of the problem.

2. Observe real people and find out what they like, what they find confusing, and what needs are currently not addressed.

3. Visualize and brainstorm the new product and how it will affect the customers, then build models and prototypes.

4. Evaluate and refine the prototypes. The designers seek feedback and go through a series of improvements. 
5. Implement the new concept. ${ }^{8}$

Our student employees don't design shopping carts, but using a similar process, they do come up with some great ideas that will benefit future BYU students.

The committee members are divided into three teams, and each team is assigned a specific project or problem. Splitting the committee members into teams allows LSAC to take on multiple challenges at the same time. Each group has no assigned leader, although leaders naturally tend to emerge. The projects are both suggested by library administration and generated by the students. LSAC meets once a week, either in small groups to brainstorm or research or as a large group to report on their projects and share ideas or to discuss an issue designated by administration. To encourage an informal atmosphere, every other week the student employees are provided with lunch.

To work on their projects, group members brainstorm and research by administering surveys and talking to students and library staff and faculty about ideas and preferences-like IDEO teams, they try to understand the problem and observe those it affects. For example, the group working on publicizing library services learned about these resources themselves by interviewing department chairs about what is available and which services are underused. Another group walked around the library and surveyed student patrons about what means of advertising they find most effective.

Based on these responses, and on their own ideas, the group members formulate suggestions and ideas to solve the initial problem - they build a "prototype" and improve upon it with suggestions from students on other teams.

LSAC members are not responsible for implementing their suggestions-they are not given the time, resources, or authority to do so. The main benefit of LSAC to the library is to provide informed, innovative ideas from a student perspective. At the end of each semester, the students formally present their research results and sugges- tions to the university librarian and the executive team.

The Lee Library recently surveyed past and present LSAC members to seek feedback on how these student employees perceive the purpose, organization, and effectiveness of the committee. The survey was anonymous and included six open-ended questions. Feedback was mostly positive: one student described LSAC as a "vehicle for change," and another said that LSAC "brings the needs of the students front and center." Members mentioned that they appreciated the opportunity to be involved in the library, to have a direct connection to administration, to make new friends, and to get free lunch. Here are some other comments from the survey:

- I enjoy the group atmosphere and camaraderie of LSAC, the collaboration of problem solving, and the brainstorming activities while discussing ways to improve the library and, in turn, the student body.

- Administration does a tremendous amount to improve our library, but LSAC provides a student's point of view.

- I loved being a member of LSAC. It gave me a greater sense of responsibility in my position in the library as an employee. It also gave me great insight into the process of making changes to a vast set-up such as the Harold B. Lee.

- I like the structure because it allows the smaller groups to work out details and then present ideas where they can get more feedback. The different groups allow us to bounce ideas off of each other and then go back to our smaller groups where we can more effectively carry out research and ideas while tackling multiple projects at the same time.

The student employees also noted some areas for improvement: they want greater accountability and stricter deadlines, as well 
as more feedback from administration on their suggestions.

But survey responses - and results of the committee itself-show that LSAC's greatest success is in creating an environment to produce some great, innovative ideas. One student said, "I really felt that all ideas were treated fairly, so I felt free to make any suggestions. I knew that we would discuss it as a group, and, if it was a good one, it would stay. It was comfortable to take some risks and really be creative."

And that is the key to creating and running successful student advisory committees, whether they are composed of student employees or volunteers-developing a process and fostering an environment where the students can brainstorm and feel comfortable taking risks and suggesting anything, even outlandish ideas, like playing music in the library.

\section{Notes}

1. Tom Kelley, The Art of Innovation (New York: Doubleday, 2001), 9.

\section{Ibid., 13}

3. Candace R. Benefiel, Wendi Arant, and Elaine Gass, "A New Dialogue: A Student Advisory Committee in an Academic Library," Journal of Academic Librarianship 25, no. 2 (1999): 111-13

4. Amy Deuink and Marianne Seiler, "Students as Library Advocates: The Library Student Advisory Board at Pennsylvania State-Schuylkill," College and Research Libraries News, January 2006, 18.

5. Deuink and Seiler, The Library Student Advisory Board: Why Your Academic Library Needs It and How to Make It Work (Jefferson, NC: McFarland \& Company, 2009).

6. Ashley Pillow, "Put SLACers to Work for Your Library: The Student Library Advisory Committee at Loyola University-New Orleans," College and Research Libraries News, November 2007, 642.

7. Roger Layton, "No Headphones Required: Public Music in the Library" (unpublished manuscript, 2010), Microsoft Word file.

8. Kelley, Art of Innovation, 6-7. n

\section{PERSONAL. ReLIAble. SERVICE.}

For over 35 years WT Cox Subscriptions has been a trusted provider of information services to libraries worldwide.

- Cost-effective, no hassle proposals

- Personal Customer Service Specialist

- Simple renewals, invoices, reports and claiming

- ILS integration, Journal Finder and eBooks
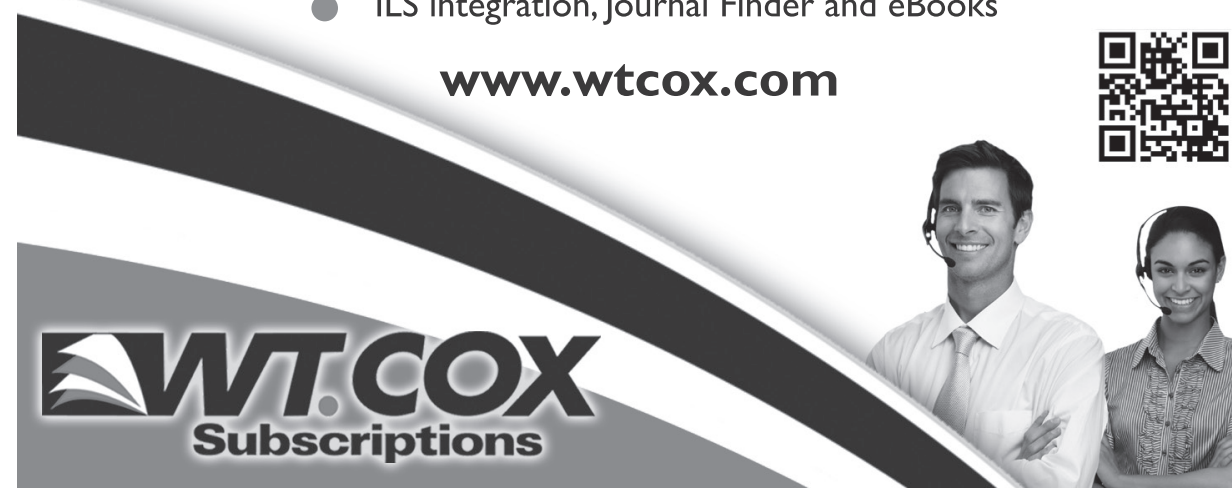